\title{
A COMPARISON OF 1980'S AND CURRENT GENERATION LOCOMOTIVE SEATS RELATIVE TO WHOLE BODY VIBRATION HEALTH EFFECTS
}

\author{
Dennis A. Mitchell, Luis Morales*
}

\section{Introduction}

A group of 1980's style locomotive seats were instrumented and tested under controlled conditions and the data was analyzed with respect to International Standards Organization's methods ${ }^{1}$ concerning whole body vibration (WBV) and potential health effects. In order to select the two worst performing seats the root-mean-square (RMS), vibration dose value (VDV) were derived for comparative purposes.

The three worst performing seats were then installed in a locomotive so that data relative to WBV could be collected and compared under actual operating conditions to current style locomotive seat data. The data was analyzed relative to WBV ISO and European guidelines concerning health. ${ }^{1-2}$

\section{Methods}

All of the 1980 style seats were initially tested per ISO $^{1}$ under controlled conditions by installing them on the same locomotive operated by the same engineer and having the WBV data collected over the same portion of track. The engineer was instructed to take the train up to 10 miles per hour and then at 2 minute increments he was to increase the velocity another 10 miles per hour until it reached 50 miles per hour for two minutes and then he was instructed to stop. Each seat test took just under 12 minutes to complete. The three worst performing seats were installed and instrumented and tested under actual operating conditions and the results from these seats were compared to current style seat data.

\section{Figure 1}

1980's style "Toadstool" seat and current generation seating

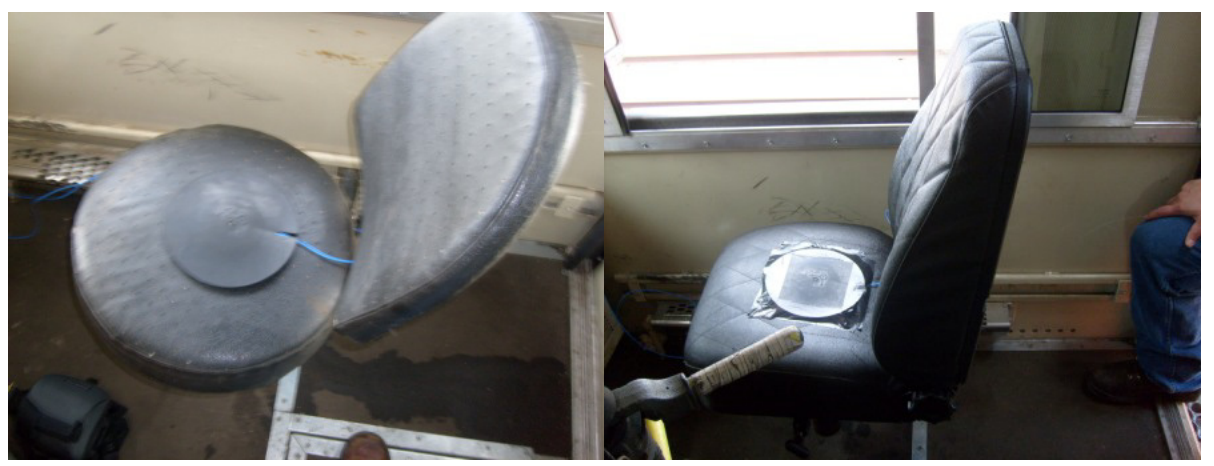




\section{Results}

The three worst performing seats were selected based on their VDV vertical axis result. The vertical $\mathrm{z}$-axis was chosen as it has been reported ${ }^{3-4}$ to have the highest vibration levels in locomotives when measured under actual operating conditions and the VDV value was chosen as it is a more accurate measure compared to RMS of the true vibration dose. Two of the 1980's style seats are commonly referred to as "toadstool" type seats and one had armrests and the other did not. The third 1980's style seat tested was in use for less than 5 years. The three 1980's style seats were installed and tested in actual operating conditions (through freight) and their average results were compared to an average from twenty five previously collected WBV runs from current style seats. All data were derived from seats installed on Burlington Northern Santa Fe (BNSF) locomotives in revenue service.

Table 1

Average WBV results from 1980's and current style seating on locomotives

\begin{tabular}{|c|c|c|c|c|c|c|c|c|c|c|}
\hline $\begin{array}{c}\text { Seat } \\
\text { Generation }\end{array}$ & $\begin{array}{c}\text { Hours of } \\
\text { exposure }\end{array}$ & \multicolumn{3}{|c|}{$\begin{array}{c}\text { RMS } \\
\left(\mathrm{ms}^{-2}\right)\end{array}$} & \multicolumn{3}{c|}{$\begin{array}{c}\mathrm{A}(8) \\
\left(\mathrm{ms}^{-2}\right)\end{array}$} & \multicolumn{3}{c|}{$\begin{array}{c}\text { VDV } \\
\left(\mathrm{ms}^{-1.75}\right)\end{array}$} \\
\cline { 2 - 11 } & & $\mathrm{x}$ & $\mathrm{y}$ & $\mathrm{z}$ & $\mathrm{x}$ & $\mathrm{y}$ & $\mathrm{z}$ & $\mathrm{x}$ & $\mathrm{y}$ & $\mathrm{z}$ \\
\hline 1980 's $(\mathrm{n}=3)$ & 5.92 & 0.17 & 0.22 & 0.28 & 0.15 & 0.19 & 0.24 & 4.45 & 5.21 & 7.39 \\
\hline 2000 's $(\mathrm{n}=25)$ & 7.20 & 0.14 & 0.21 & 0.25 & 0.13 & 0.17 & 0.21 & 3.42 & 4.47 & 5.69 \\
\hline
\end{tabular}

\section{Discussion}

The average WBV results summarized in Table 1 fall below the health guidance caution zone as outlined in the $\mathrm{ISO}^{1}$ document and are below the daily exposure action value of $0.5 \mathrm{~ms}^{-2}$ for $\mathrm{A}(8)$ and $9.2 \mathrm{~ms}^{-1.75}$ for VDV as outlined in the European Directive. It is clear that the 1980 style seats have higher WBV data values compared to the current generation of seats, however the 1980 style seats were still below current WBV health guidelines. The current generation of locomotive seating also offers more comfort and ergonomic features than their 1980's counterparts. Locomotive seats that have active vibration dampening devices are currently under development and these seats may offer further WBV performance improvements over the current generation.

\section{References}

1. ISO 2631-1, Mechanical vibration and shock-Evaluation of human exposure to whole-body vibrationPart 1: General requirements (1997-07-15).

2. Directive 2002/44EC of the European Parliament and of the Council of 25 June 2002 on the minimum health and safety requirements regarding the exposure of workers to the risks arising from physical agents (vibration).

3. Johanning, E., Fischer, S., Christ, E., Gores, B., and Landsbergis, P. (2002). Whole-body Vibration Exposure Study in U.S. Railroad Locomotives- An Ergonomic Risk Assessment, AIHA Journal 63:439446.

4. Cooperrider, N.K. and Gordon, J.J. (2008). Shock and Impact Levels on North American Locomotives, Journal of Sound and Vibrations, 318:809-819. 